\title{
Migrando por el cine marroquí
}

\section{Migrating through Moroccan cinema}

Fechas | En edición: 18/05/2021 - Publicación final: 01/07/2021

\section{Dra. Lara-María ESPINAR}

Universidad de Málaga. España. espinarmedina@gmail.com

https://orcid.org/0000-0003-2822-3663

\section{Migrando por el cine marroquí}

Autora: L. PERALTA-GARCÍA

Madrid: Fragua, 2018.

218 páginas

ISBN: 978-84-7074-821-9

\section{Resumen}

Migrando por el cine marroquí propone un circuito a través de los mitos, las metáforas, los imaginarios y la mentalidad de las personas migrantes tal y como los y las cineastas marroquíes las contemplan a través de sus narrativas fílmicas. Un libro que continúa los trabajos anteriores de la autora y que tiene como binomio protagonista al cine y las migraciones. Pero desde la mirada y el trabajo de los y las cineastas marroquíes, ofreciendo así una mirada propia de las migraciones desde y en el país, lejos de la visión occidentalizada que protagoniza las películas europeas, en el que no existe migración más allá de la tragedia de la patera, conformando así una visión reduccionista de un fenómeno tan amplio y diverso.

\section{Palabras clave}

Cine marroquí; migraciones; comunicación; Marruecos; España

\begin{abstract}
Migrating through Moroccan cinema proposes a circuit through the myths, metaphors, imaginaries and mentality of migrants as Moroccan filmmakers contemplate them through their filmic narratives. A book that continues the previous works of the author and whose protagonist binomial is cinema and migrations. But from the point of view and the work of Moroccan directors, thus offering a view of migrations from and within the country, far from the Western vision that stars in European films, in which there is no migration beyond the tragedy, thus conforming a reductionist vision of such a wide and diverse phenomenon.
\end{abstract}

\section{Keywords}

Moroccan cinema; migrations; communication; Morocco; Spain 
Migrando por el cine marroquí es mucho más que un libro sobre cine migratorio marroquí. Es una obra que habla de nuestra historia contemporánea vista desde el país vecino. Marruecos es uno de los países con mayor tasa migratoria del mundo. Se estima que unos tres millones de marroquíes viven en el extranjero. Desde los primeros movimientos internos del campo a la ciudad en la década de los 50, el cine marroquí de la post-independencia ha sido testigo y acompañante de los grandes hitos de los siglos XX y XXI: las migraciones económicas, la búsqueda de un espacio de libertad personal, el fenómeno de la patera, la vida en el extranjero o la vuelta a casa. Pero también de movimientos de carácter histórico menos mediatizados, como los derivados de la presencia colonial en el país vecino, el éxodo de los judeo-marroquíes a Palestina o la participación de los "exóticos" en la Segunda Guerra Mundial.

Migrando por el cine marroquí propone un circuito a través de los mitos, las metáforas, los imaginarios y la mentalidad de las personas migrantes tal y como los y las cineastas marroquíes las contemplan a través de sus narrativas fílmicas. En palabras de José María Perceval (autor del prólogo), se trata de una investigación académica hilada "con la pasión de una amante del cine", una obra que plasma "el trabajo de una profesional competente y de una militante convencida".

El cine, como afirma la autora, Lidia Peralta, es una herramienta artística que puede presentar las imágenes vivas de una sociedad concreta y su estructura de pensamiento, al tiempo que contribuye al diálogo desde propuestas de expresión creativa y estética. Ciertamente, los y las artistas están profundamente arraigados a los discursos sociales en los que operan. Las creaciones cinematográficas actúan junto a la historiografía y otros campos socio-políticos como agentes que otorgan sentido a una realidad cultural concreta, son espejos en los que mirarse. Una de las tesis del libro es que el cine nos puede ayudar a comprender fenómenos que tradicionalmente han quedado muy mediatizados y apegados a discursos interesados desde una mirada colonial y eurocéntrica. El cine migratorio contribuye, afirma la autora, a transformar la sociedad en un orden social más justo y democrático.

Este libro sigue una línea coherente con otros trabajos previos de la autora sobre cine y migraciones (Los nuevos héroes del siglo XXI: las migraciones subsaharianas vistas por el cine en España y África, UOC Press). Si en propuestas previas analizaba el cine español, en esta ocasión atraviesa el Estrecho de Gibraltar para tratar de profundizar y comprender, a través de un nutrido número de entrevistas a cineastas de referencia en Marruecos y el análisis cualitativo y cuantitativo de las películas, otras miradas en torno al fenómeno migratorio. Miradas alejadas de los discursos hegemónicos occidentales, miradas fuertemente impregnadas del espíritu migratorio.

Un libro que continúa los trabajos anteriores de la autora y que tiene como binomio protagonista al cine y las migraciones. Pero desde la mirada y el trabajo de los y las cineastas marroquíes, ofreciendo así una mirada propia de las migraciones desde y en el país, lejos de la visión occidentalizada que protagoniza las películas europeas, en el que no existe migración más allá de la tragedia de la patera, conformando así una visión reduccionista de un fenómeno tan amplio y diverso. Narrar el cine migratorio marroquí aporta las necesarias visiones desde el propio contexto socio-cultural.

Como dice la autora, a su vez realizadora del documental asociado al libro Los nuevos héroes del siglo XXI: Las migraciones subsaharianas vistas por el cine en España y África (2017), "En lo cinematográfico, haber tenido documentales propios circulando por los festivales de cine en Marruecos, me abrió unas puertas insospechadas al cine, o mejor dicho, a los cines marroquíes. Porque igual que no existe un solo Marruecos, no existe un solo cine marroquí" (20). Esta es la diversidad que se desprende de las páginas del libro. Sin fetichismos estéticos, sin adscripciones a escuelas concretas, la autora lleva a cabo un recorrido muy coherente por una temática tan actual como necesitada de miradas diversas.

En el primer capítulo Lidia Peralta analiza el contexto y evolución de las migraciones en Marruecos. Se adentra en el segundo capítulo en las características y tendencias generales del cine marroquí, para abordar a continuación de forma más detallada el cine migratorio. Mantiene la autora que hablamos de una realidad con entidad propia y para ello aporta los resultados de su investigación, basada en el análisis de 327 películas contenidas en el catálogo del Centre de la Cinématographie Marocaine. Junto al impacto cuantitativo y la evolución temática, Peralta trata de definir en qué consiste lo que ella ha definido como "mirada interna" del fenómeno migratorio, una mirada que hace referencia a las propias historias de los y las cineastas cuyas vidas están impregnadas por las experiencias migratorias, propias, de familiares o antepasados. En el tercer capítulo, la obra hace un recorrido por esta "mirada interna" de cineastas como Hassan Benjelloun, Mohamed Ben, Mostafa Deskaoui, Jilali Ferhaty o Hakim Belabbes, entre otros. Las entrevistas realizadas a cineastas marroquíes, esparcidas y fragmentadas a lo largo del libro, dan cuenta de experiencias muy cercanas a las vivencias migratorias. Examina además el nutrido rastro académico que el estudio del cine marroquí ha aportado hasta la fecha.

El cine migratorio en Marruecos es un género en sí mismo, como defiende Lidia Peralta y también así lo muestran los datos de sus análisis: de las 327 películas incluidas en el catálogo del Centro de 
la Cinématographique Marocain ente 1958 y 2015, 96 de ellas (un 29\%), tratan aspectos migratorios, ya sea de manera principal, secundaria o transversal. Las migraciones interesan a las y los cineastas marroquíes. Sin embargo, no existía hasta la fecha estudio que ofreciera visiones generales de los temas migratorios y su evolución en el cine marroquí.

Migrando por el cine marroquí es un viaje por esas más de 90 películas catalogadas en cinco grandes bloques temáticos: el éxodo rural, la primera etapa de las migraciones marroquíes; las migraciones históricas; las migraciones a otros países; la vida en el extranjero, fundamentalmente Europa; y el retorno a casa.

A partir de una primera parte introductoria y de contexto, Peralta nos invita a viajar por las películas y sus contextos de realización, así como por los avatares narrativos más destacados de las mismas, comenzando por el éxodo rural de los años 50, es decir, las migraciones internas, el primer gran movimiento migratorio en Marruecos, propiciado a partir de la colonización del país. Continúa con un capítulo de interés dedicado a las migraciones de carácter histórico, alumbrando perspectivas poco tratadas hasta la fecha. El recorrido se completa con las migraciones al extranjero, con un apartado especial hacia los viajes que se llevan a cabo con riesgo de vida y sin permisos, aquellas eufemísticamente llamadas inmigraciones ilegales o clandestinas, expresiones que Peralta rechaza por inducir argumentos contrarios al derecho a la movilidad de las personas. En esta parte la autora no pierde la oportunidad para poner el foco en los colectivos más vulnerables, fundamentalmente mujeres y niños, pero también ciudadanos y ciudadanas del África Subsahariana, dedicándoles un amplio bloque: "Las mujeres en ruta", "Las mujeres en espera", "La no-infancia de los menores migrantes" y "La cuestión subsahariana". El capítulo séptimo, sobre la vida en el extranjero, da cuenta a través de las narraciones fílmicas de los problemas que las personas migrantes afrontan en el lugar de destino como son la explotación laboral, las cuestiones identitarias o el choque entre "la realidad esperada y la realidad encontrada". Le sigue un capítulo que trata la vuelta a casa, episodio que analiza el regreso a Marruecos de migrantes y descendientes de migrantes que retornan a su tierra ya sea por motivos de muerte o enfermedad de familiares o bien empujados por motivaciones identitarias. La obra finaliza con un apartado dedicado a las conclusiones del estudio que recogen las principales características del cine migratorio marroquí. Un total de nueve capítulos que reflejan la realidad cíclica de las migraciones.

La obra de Lidia Peralta da la visibilidad requerida al cine migratorio marroquí y lo define en base a una serie de características concluyentes, como que casi el $30 \%$ de las películas marroquíes aborda temas migratorios, o la indisoluble relación entre realidad social y realidad cinematográfica, que empezó a hacerse patente cuando Marruecos fue consciente del fenómeno del éxodo rural en las décadas de los 70 y 80 , hasta la narrativa de las vidas de las y los migrantes en Europa, a partir de los 2000. No hay duda, afirma Peralta, de que el cine marroquí ha estado siempre ahí, "cubriendo cada arista del proceso migratorio desde la expresión artística" (102).

Estamos ante un libro que sienta las bases del cine migratorio marroquí, hasta ahora solamente tratado a través de estudios de caso, como bien indica la autora (21), y por tanto está llamado a convertirse en un documento de interés y referencia no solo para personas interesadas en los temas migratorios en general, sino en el cine marroquí de forma particular. 